\title{
Organic and Psychogenic Causes of Sexual Dysfunction in Young Men
}

\author{
Brian Dick ${ }^{1}$, Amit Reddy ${ }^{1}$, Andrew T. Gabrielson ${ }^{1}$, Wayne John Hellstrom 1," \\ ${ }^{1}$ School of Medicine, Tulane University, New Orleans, USA
}

Corresponding Author: Wayne John Hellstrom, MD, School of Medicine, Tulane University, New Orleans, LA 70118, USA. E-mail: whellst@tulane.edu

Received September 10, 2017; Accepted December 12, 2017; Online Published December 25, 2017

\begin{abstract}
Sexual dysfunction, specifically erectile dysfunction (ED), premature ejaculation (PE), and delayed ejaculation (DE), are debilitating diseases, especially in young men. The past decade has seen an increase in the number of young men (under 40 years of age) presenting to their physician with sexual dysfunction. Traditionally, sexual dysfunction in young men was viewed as a strictly psychosomatic problem stemming from underlying psychogenic causes such as anxiety or insecurity. While this is true in some cases, the advent of new diagnostic tools and pharmacotherapy have revealed that the prevalence of organic causes for these diseases is much higher than previously thought. In reality, many patients present with primarily organic sexual dysfunction that then triggers concomitant psychogenic stressors such as anxiety and depression which exacerbate their problem. This review focuses on the common etiologies of sexual dysfunction experienced by young men in order to help educate clinicians so that they may better understand, identify, and serve this growing patient population.

Keywords: Young Men; Erectile Dysfunction; Premature Ejaculation; Delayed Ejaculation; Etiologies

Citation: Dick B, Reddy A, Gabrielson AT, Hellstrom WJ. Organic and psychogenic causes of sexual dysfunction in young men. Int J Med Rev. 2017;4(4):102-111. doi: 10.29252/ijmr-040404.
\end{abstract}

\section{Introduction}

Identifying the cause of a young man's sexual dysfunction begins with a detailed history and physical examination. Patients may be reluctant to share details of their sexual habits or difficulties because of shame or embarrassment. Care must be taken when asking questions about the onset, duration, severity, and patient-suspected etiology of a man's condition. Young men with sexual dysfunction and no history of trauma or systemic disease are often particularly challenging to treat. They typically present with one or more of the following: unrealistic expectations of a cure, an underlying psychiatric illness (anxiety, depression), performance anxiety, relationship problems, excessive preoccupation with disease, and/or a high-stress occupation. $^{1}$

These patients are usually technologically literate and come to the physician already having done extensive cyber research about the possible etiologies of their dysfunction. This can be problematic if the patient has already performed self-diagnosis, as he will often request unnecessary diagnostic testing after a thorough history and physical exam have been performed..$^{2}$ It is important for the physician to establish an early rapport with the patient and assure him that by working together, better outcomes can be achieved.
Erectile Dysfunction
Epidemiology
Erectile Dysfunction (ED) is defined by the International Society for Sexual Medicine (ISSM) as the consistent or recurrent inability to attain and/or maintain penile erection sufficient for sexual satisfaction. ${ }^{3}$ Traditionally, ED has been viewed as an age-dependent condition, with 70 -year-olds being affected three times more than 40 - year-olds. ${ }^{4}$ Because of this, men under 40 (henceforth referred to as "young men") are often overlooked in studies, making it difficult to identify accurate prevalence estimates of young men with ED. Three post-2014 studies on young men in Canada, Brazil, and the United States reported ED rates of $23.7 \%, 35 \%$, and $33 \%$, respectively. ${ }^{5-7}$ While there is good variation between these studies, it should be noted that the rates are significantly higher than those from a 1999 study that reported an ED rate of only $8 \%$ in young men. ${ }^{8}$ This trend of increasing ED prevalence in men under 40 has been seen at the University of Florence Sexual Medicine 
and Andrology Unit. In 2011, around 5\% of their patients complaining of ED were under the age of 40. By 2016, that number had increased to $14.2 \% .^{9}$ Historically, ED in young men was assumed to be psychological in nature. However, new diagnostic tools, including penile duplex ultrasonography, standardized questionnaires, and endocrine evaluations, have provided enhanced evaluations of ED and revealed several organic etiologies. These organic components have been found to play a role in anywhere from $14.8 \%$ to $87 \%$ of ED cases in men under $40 .{ }^{10,11}$
Organic ED typically has a gradual onset while patients maintain normal libido. Psychogenic ED typically presents with a sudden onset, decreased libido, and most importantly, the ability to still achieve high-quality erections during self-stimulation. ${ }^{12}$

With an increasing population of young men experiencing ED, it is important that physicians be able to differentiate between organic and psychogenic etiologies. Additionally, understanding that many patients are experiencing a mix of psychogenic and organic etiologies is crucial to providing optimal care.

\begin{tabular}{|c|c|c|}
\hline Erectile Dysfunction & Premature Ejaculation & Delayed Ejaculation \\
\hline Cardiovascular & Endocrine & Endocrine \\
\hline Arterial insufficiency & Hyperandrogenism & Hypoandrogenism \\
\hline Subclinical endothelial dysfunction & Hypoprolactinemia & Hyperprolactinemia \\
\hline Endocrine & Hyperthyroidism & Hypothyroidism \\
\hline Hypogonadism & Neurological & Neurological \\
\hline Hypo/hyperthyroidism & 5-HT1a overexpression & 5-ht1a underexpression \\
\hline Type 2 diabetes mellitus & 5-HT2c underexpression & 5-ht2c overexpression \\
\hline Isoflavones (i.e. Daidzein) & Infectious & \\
\hline Neurological & Chronic prostatitis & \\
\hline \multicolumn{3}{|l|}{ Multiple sclerosis } \\
\hline \multicolumn{3}{|l|}{ Epilepsy } \\
\hline \multicolumn{3}{|l|}{ Femoral fracture } \\
\hline \multicolumn{3}{|l|}{ Lumbar spine surgery } \\
\hline \multicolumn{3}{|l|}{ Medication } \\
\hline \multicolumn{3}{|l|}{ SSRIs } \\
\hline \multicolumn{3}{|l|}{ NSAIDs } \\
\hline \multicolumn{3}{|l|}{ Finasteride } \\
\hline Anti-epileptics (i.e. Topiramate) & & \\
\hline
\end{tabular}

\section{Organic Etiologies}

The organic components of ED can be classified into three major categories: cardiovascular, endocrine, and neurogenic conditions.

\section{Cardiovascular}

The most common cardiovascular complications associated with ED are focal artery occlusive disease and subclinical endothelial dysfunction. Focal artery occlusion is caused through direct trauma or the chronic underlying thyroid dysfunction may be important for restoring normal erectile function in this category. There is a strong association between type 2 diabetes and ED, with some diabetic populations having prevalence rates as high as $75 \% .{ }^{13}$ Fedele et al. observed ED incidence in diabetics to be 68 cases per 1000 patients per year compared to 25.9 cases per 1000 patients per year in the general population. ${ }^{14}$ As the rate of early-onset type 2 diabetes continues to rise, it is expected that the prevalence of ED in young men will continue to increase. Another endocrine-related cause of ED is Kleinfelter's syndrome. Kleinfelter's syndrome patients will demonstrate low serum testosterone, elevated follicle stimulating hormone, luteinizing hormone, and often elevated estradiol levels. ${ }^{15} \mathrm{ED}$ in these patients is hypothesized to be associated with low testosterone levels. ${ }^{16}$ There are other less common causes of endocrine-related ED, with one example being a highsoy diet. The soy isoflavone daidzein has been documented to cause ED in rats, ${ }^{17}$ and there was a reported case of an 18-year-old male who developed hypogonadal ED while on a high-soy vegan diet. ${ }^{18}$

repetitive compression of vascular structures. Bicycling is likely the main etiology of focal artery occlusion disease related to ED. ${ }^{19}$ A survey of 160 males competing in a $540-\mathrm{km}$ race found that $13 \%$ had symptoms of temporary new-onset impotence by the end of the race. ${ }^{20}$ A theory on how this occurs is that perineal compression inhibits arterial flow to the penis, activating transforming growth factor- $\beta 1$ (TGF $\beta-1)$. This could drive the development of ED through the synthesis of collagen and connective tissue in the corpus cavernosa and apoptosis of the trabecular smooth muscle. ${ }^{21}$

Subclinical endothelial dysfunction can be assessed by measuring systolic blood pressure, C-reactive protein levels, cholesterol, triglycerides, and carotid intimalmedia thickness. A study by Yao et al. compared subclinical endothelial dysfunction in 40 young men with ED to age-matched controls without ED. They found that the ED group had an elevated (but still within normal clinical range) systolic blood pressure, C-reactive protein level, cholesterol, triglycerides, and carotid intimal-media thickness. ${ }^{22}$ This suggests that patients with ED may have subclinical cardiovascular risk factors without presenting with obvious signs of systemic cardiovascular disease. 


\section{Endocrine}

All hormones either directly or indirectly regulate desire, erection, ejaculation, and orgasm, and, as such, hormonal deficiencies or imbalances are other significant causes of sexual dysfunction. ${ }^{23}$ Endocrine disorders are seen less often in younger men than in their older counterparts. For example, only $4 \%$ of healthy men under the age of 50 with ED had problems with low testosterone. $^{24}$ The most common endocrine-related disorders seen in younger ED patients are thyroid dysfunction, diabetes, and Kleinfelter's syndrome. ${ }^{24}$ In a study by Krassas et al., patients with an untreated thyroid dysfunction were administered the validated Sexual Health Inventory for Men (SHIM) 5-item questionnaire to assess erectile function. Their results were matched to controls and found to show higher levels of ED in both hypo- and hyperthyroidism. Patients were then treated for their thyroid dysfunction. No difference in SHIM scores was found between the controls and treated patients at the one-year follow up. ${ }^{25}$. Hence, attention to

\section{Neurogenic}

The neurological system is closely associated with erectile function. Erectile physiology is dependent on peripheral, spinal, supraspinal, somatic, and autonomic pathways. Common neurological etiologies of ED include multiple sclerosis, epilepsy, femoral fractures, and lumbar spine procedures. Young men with multiple sclerosis are 2.23 times more likely to develop ED than their age-matched peers. ${ }^{26}$ Keller et al. noted that young men aged 30-39 with ED were three times more likely than controls to have been previously diagnosed with epilepsy. ${ }^{27}$ Men who had a femoral fracture repaired with intramedullary shaft nailing were more likely to experience ED than similar patients who experienced tibial fracture ( $40.5 \%$ vs $12.5 \%$ ). The mechanism for this is believed to be damage to the pudendal nerve. ${ }^{28}$ Lastly, $34 \%$ of men under the age of 50 undergoing lumbar spine surgical decompression experienced post-surgical ED. ${ }^{29}$

\section{Psychogenic Etiologies}

There is a well-known link between psychiatric conditions and ED in older patients. ${ }^{30}$ Depression has shown a particularly strong association, with the extent of depression correlating with the severity of erectile impairment. ${ }^{31}$ Several studies examined younger men to determine the extent to which psychogenic factors were involved in ED. A study of 800 North American medical students showed a significant association between depression and ED. ${ }^{32}$ Similarly, Mialon et al. surveyed over 3,800 Swiss army men aged 18-25 and found a link between ED and depression. ${ }^{33}$ In both of these studies, however, it was unclear if the ED caused the depression or vice versa. It is likely a bidirectional relationship. Patients with ED may become depressed because of their symptoms, and, as the depression worsens, it acts to inhibit erectile ability. It is important to identify patients early in this negative cycle before the depression becomes too severe and further complicates the ED treatment.

A study of 3,500 18- to 48-year-olds in Finland established anxiety to be another psychogenic causative factor of ED. Furthermore, ED was less common in men with longer sexual lives (defined as time since first sexual intercourse), which may highlight the positive roles of self-esteem and sexual experience. ${ }^{34}$ As with depression, the relationship between ED and anxiety is likely bidirectional. A man who is excessively worried about his ability to achieve an erection is distracted from arousal and, as a result, may have diminished erectile function. This becomes a vicious feedback loop where negative sexual experiences lead to a lack of self-esteem or increased anxiety that perpetuates subsequent negative sexual experiences.

In addition to distracting from arousal, anxiety-induced ED can also be explained biochemically. Anxiety elevates levels of noradrenaline, the primary erectolytic (antierectile) neurotransmitter. ${ }^{35}$ The relationship between ED and premature ejaculation may also be psychogenic in nature and will be discussed later.

\section{Medication-Induced ED}

While psychological conditions such as depression have been extensively linked to ED, a subset of individuals, including young men, experience ED not as a result of their psychological condition, but as a side effect of the medications used to treat their psychiatric illness. Selective serotonin reuptake inhibitors (SSRIs) are prescribed to patients to manage a variety of disorders including depression, obsessive-compulsive disorder, post-traumatic stress disorder, and anxiety. Patients often complain of genital anesthesia and associated ED, not only while taking SSRIs, but also for some time after their discontinuation. The genital anesthesia and associated delayed ejaculation effect of SSRIs will be discussed in a later section. The exact mechanism through which SSRIs cause ED is not agreed upon, but several theories involve epigenetic gene expression, cytochrome actions, dopamine-serotonin interactions, and downregulation of 5-hydroxytryptamine receptor 1A. ${ }^{36}$ Non-steroidal anti-inflammatory drugs (NSAIDs), one of the most commonly used medications by all agegroups, are also linked to ED. NSAIDs are inhibitors of cyclooxygenase I and II (COX I and II). COX I and II are involved in the synthesis of prostaglandins and bradykinins, which are involved in vasodilation. A $20 \mathrm{ug}$ intracavernosal injection of prostaglandin E1 is documented to increase the maximum velocity of the cavernosal arteries, stimulating erection. ${ }^{37}$

Thus, it follows that NSAIDs may interfere with erectile function. A 2011 study by Gleason et al. examined ED prevalence in habitual NSAID users and nonusers. After adjusting for comorbidities, there was an association between NSAID use and ED. While the study's target age group was men older than 45 , similar results were found among all measured age groups. ${ }^{38}$ 
Finasteride is another common medication with ED risks that is used by men under 40 , as finasteride is used for reversal or prevention of male pattern baldness. A clinical trial involving 1553 men revealed 1.4\% of men taking finasteride experienced ED as an adverse event compared with $0.9 \%$ of men using a placebo. ${ }^{39}$ Lastly, antiepileptic medications have been linked to ED. Normal plasma levels of testosterone were observed in two ED patients taking the anti-epileptic drug topiramate, leading researchers to believe the mechanism of inhibition is vasogenic. ${ }^{40}$ Many other medications suggest ED as a side effect, but to list them all would be outside the scope of this review.

\section{Preventative Strategies}

Current research has revealed several new factors to consider when diagnosing young men presenting with ED. Mykoniatis et al. assessed the consumption of antioxidants, specifically flavonoids, in young men with ED and found that, compared to controls, men with ED had a lower monthly intake of flavonoids. They also found that the consumption of $50 \mathrm{mg}$ flavonoids/day lowered ED risk by $32 \% .{ }^{41}$ Cigarette smoking has been reviewed extensively and shown to contribute to ED in all age groups. ${ }^{42-45}$ Interestingly, cigarette smoking may have more of an impact on erectile function in younger men than it does in older men. ${ }^{46}$

\section{Treatment of ED}

Because of their effectiveness and ease of use, the most common treatment for ED is oral phosphodiesteride5 (PDE5) inhibitors. ${ }^{16}$ PDE5 inhibitors are of particular interest to this review, because they seem to affect a patient's psychological well-being as well as their ED. Yang et al. assessed over 700 men with a mean age of 38 for Self Esteem and Relationship (SEAR) scores before treatment and four weeks after treatment with PDE5 inhibitors. They noted improvements in overall SEAR scores as well as improvements in SHIM scores. ${ }^{47}$

Kennedy et al. evaluated depressive symptoms and erectile function in 202 men diagnosed with clinical ED and randomized them to a six-week double-blinded treatment with placebo or a PDE5 inhibitor.

When compared to the control group, the group receiving a PDE5 inhibitor revealed significant improvements in both erectile function and depressive symptoms. ${ }^{48}$ These studies exemplify the intricate and often bidirectional relationship between ED and psychological symptoms.

Several other interventions for ED in young men are vacuum-assisted erection devices, intracavernosal injections, counseling for patients with predominantly psychogenic ED, and in the case of refractory cases, prosthetic surgery. To describe them all, however, would be outside the scope of this review.

\section{Premature Ejaculation}

Epidemiology

Premature Ejaculation (PE) is another sexual dysfunction that often affects young men. An Italian study that reviewed calls received by a sexual helpline between 2006 and 2008 found that PE was the most common complaint of male callers (14.7\%), and the most represented age group was 26-35 years old. ${ }^{49}$ However, the prevalence of PE is difficult to measure, and there is no consensus about true prevalence estimates. Three studies in 2013 assessed males with a Premature Ejaculation Diagnostic Tool (PEDT) and reported scores of $\geq 11$ in $11.3 \%,{ }^{50} 12.1 \%,{ }^{51}$ and $50 \%{ }^{52}$ of their sample populations. The discrepancies in reported rates of $\mathrm{PE}$ can be partially explained by two factors. First, there is a negative stigma associated with the condition that may lead to under-reporting. Second, the ISSM and the Diagnostic and Statistical Manual of Mental Disorders, Fifth Edition (DSM-V-TR) have different definitions of $\mathrm{PE}$, which leaves room for various interpretations by the physician. For convenience, this review uses the definition of $\mathrm{PE}$ as provided by the ISSM, which is a male sexual dysfunction characterized by ejaculation that always or nearly always occurs before or within approximately 1 minute of vaginal penetration (intravaginal ejaculatory latency time [IELT]) from the first sexual experience (lifelong PE) or a clinically significant and bothersome decrease in latency time, often to approximately 3 minutes or less (acquired PE); the inability to delay ejaculation on all or nearly all vaginal penetrations; and negative personal consequences, such as distress, bother, frustration, and/or the avoidance of sexual intimacy. ${ }^{3}$ In addition to lifelong $\mathrm{PE}$ and acquired $\mathrm{PE}$, natural variable $\mathrm{PE}$ and premature-like ejaculatory dysfunction have been proposed as unique PE syndromes. Young men with natural variable PE only have PE occasionally. ${ }^{53}$ Young men with premature-like ejaculatory dysfunction present with complaints of PE while having IELTs in the normal range (5-20 mins). ${ }^{53}$ The distinction between these four types of PE are important, as they help the physician determine whether the underlying cause of $\mathrm{PE}$ is organic or psychogenic in nature. Premature-like ejaculatory dysfunction is believed to be more psychogenic in nature than either lifelong PE or acquired PE. ${ }^{53}$ Meanwhile, natural variant PE is believed to be caused by normal variations in IELTs and therefore does not have a cause. ${ }^{53}$ The type of PE a patient has can be ascertained from a detailed sexual history.

\section{Organic Etiologies}

Chronic prostatitis, neurobiology, genetics, and endocrine risk factors are all believed to be organic components of PE. Chronic prostatitis is an inflammation of the prostate that can cause constipation, diarrhea, urinary symptoms (frequency, hesitancy, painful micturition), and pain (perineal, scrotal, supr- 
apubic).$^{54}$ Screponi et al. studied 46 men with PE and found $56.5 \%$ to have prostatic inflammation. ${ }^{55}$ Bartoletti et al. reviewed 5,540 Italian men and recorded 764, median age 34.9 years, with symptoms related to chronic prostatitis. They showed significantly higher rates of PE than age-matched controls. ${ }^{54}$ While these two studies suggest a link between chronic prostatitis and PE, the pathophysiology of the relationship is unknown at this time. Examining the neurobiology behind erection and ejaculation reveals another organic component of PE. There is a 5-HT1A serotonin subtype receptor that is documented to lead to shorter ejaculatory times when stimulated in rats. ${ }^{56}$ Additionally, there is a 5-HT2C serotonin subtype receptor that is revealed to lengthen ejaculatory times when stimulated in rats. ${ }^{56}$ It follows that PE may be caused by biological diversity between the expression of 5-HT1A and 5-HT2C receptors. Patients with PE may have hypersensitive or overexpression of 5HT1A receptors as well as hyposensitive or underexpression of 5-HT2C receptors. Human studies to verify these mechanisms have been complicated by the fact that most serotonergic drugs non-specifically activate multiple receptors types. ${ }^{57}$ Variable expression of 5-HT1A and 5-HT2C receptors could also be an explanation of the genetic component to PE. Males with under- or overexpression of either receptor may pass those traits on to their offspring, thereby passing on PE. Jern et al. examined this genetic component in a study of 1,196 Finnish male twins and found a moderate genetic influence (28\%) on PE. ${ }^{58}$

As previously mentioned, hormonal imbalance or insufficiency can be the root of many sexual dysfunctions. $^{23}$ Sex steroids, prolactin, and thyroid hormones all affect IELT. This section will focus on the mechanisms for PE, and delayed ejaculation will be discussed later. The sex steroid testosterone plays an important role in sexual desire, spontaneous sexual thoughts, and attraction to erotic stimuli.

As previously mentioned, underexpression of testosterone is associated with ED. On the other hand, the overexpression of testosterone is associated with PE. A study of 2,437 men by Corona et al. observed significantly elevated total testosterone and free testosterone in men under 40 with PE compared to those without PE. ${ }^{59}$ One explanation for this relationship is a testosterone-induced upregulation of PDE5 in the vas deferens, prostate, and seminal vesicles. ${ }^{60}$ The relationship between prolactin and $\mathrm{PE}$ can be understood through the effect prolactin has on testosterone. Prolactin secretion in males inhibits pulsatile secretion of gonadotropin-releasing hormone and can lead to secondary hypogonadism. ${ }^{61}$ As previously stated, hyperandrogenism is associated with $\mathrm{PE}$, so it is expected that lower levels of prolactin are associated with PE. This was confirmed by a study of 2,531 men by Corona et al. in which men in the lowest prolactin quartile manifested a higher risk of $\mathrm{PE} .{ }^{62}$
Hyperthyroidism is also associated with PE. A study of 34 men with hyperthyroidism and 14 with hypothyroidism documented a PE prevalence of $50 \%$ and $7.1 \%$, respectively. ${ }^{63}$ After thyroid hormone was brought to normal levels, PE prevalence dropped to $15 \% .{ }^{63}$ The mechanism behind the relationship of PE and thyroid hormone is uncertain, but three potential sites of action are the endocrine/paracrine pathway, the sympathetic nervous system, and the serotoninergic pathway. ${ }^{64}$

\section{Psychogenic Etiologies}

Historically, PE has been associated with psychogenic factors. Performance anxiety, guilt, depression, and fear have all been suggested as PE causes. ${ }^{65}$ A 1998 study in England found anxiety (as measured by the Hospital Anxiety and Depression Scale) to have the highest association with PE, with an odds ratio of 3.1 after adjustment for age. ${ }^{65}$ One suggested mechanism for this association is that anxiety activates the sympathetic nervous system in patients, which results in a lowered ejaculatory threshold. ${ }^{64}$ However, it is unclear if anxiety is causative or a result of PE. Does anxiety shorten a young man's IELT, or is the young man anxious because of his short IELT? All that is certain is that during sex, men with PE worry significantly more about control of ejaculation and the possibility of failure than those without PE. ${ }^{66} \mathrm{ED}$ may also be a psychogenic cause of PE. A study of 1,680 men with ED were assessed for severity using the International Index for Erectile Function (IIEF) and screened for PE. PE was noted in $52.4 \%$ of men with severe ED compared with only $29.5 \%$ of men with mild ED. ${ }^{67}$ However, this relationship is likely bidirectional. Some men with ED may ejaculate quickly to conceal that they cannot maintain an erection. These men would present to the clinic with PE and likely benefit from ED treatments. On the other hand, men with lifelong PE may negatively view their sexual history and develop ED because of it. These patients would benefit from treatment for the underlying PE. ${ }^{68}$

Premature-like ejaculatory dysfunction is the one subset of PE believed to be predominantly due to psychological problems or relationship issues. It is the subset of $\mathrm{PE}$ described by Waldinger et al. as patients who have normal to long IELTs, yet still complain of PE. Treatment with ejaculation-delaying medication is advised against..$^{33}$ Over time, arguments for a psychogenic basis of lifelong and acquired PE have failed to be convincingly verified. ${ }^{66}$ Furthermore, the discovery that certain SSRIs can delay ejaculatory time, as will be discussed in the next section, has made a strong case for acquired and lifelong $\mathrm{PE}$ to be predominantly organic in nature.

Treatment of PE

Historical treatment options for PE include dapoxetine and other SSRIs, tramadol and other topical anesthetics, 
PDE5 inhibitors for PE with concomitant ED, and behavioral therapy. ${ }^{69}$ Newer experimental treatment methods include the use of DA-8031 (an SSRI), oxytocin antagonists (i.e. epelsiban and IX-01), alpha-blockers, modafinil, and botulinum-A toxin. ${ }^{69}$ SSRI treatment is of particular interest, as it effects both PE and ED. SSRIs lead to increased activation of the aforementioned 5HT2C serotonin receptor, causing a lengthened IELT. ${ }^{57}$ Additionally, they are documented to cause ED in some patients, although the mechanism is less well described. ${ }^{36}$ A patient presenting with $\mathrm{PE}$ due to organic causes may greatly benefit from treatment with SSRIs. On the other hand, a patient presenting with PE secondary to ED will not benefit from treatment with an SSRI, and the drug will likely exacerbate their problem. Taking the time to get a thorough sexual history and properly classify a patient's sexual dysfunction is central to providing effective treatment.

\section{Delayed Ejaculation}

Epidemiology

Whereas young men with PE have significantly shorter IELTs than normal, young men with delayed ejaculation (DE) have significantly longer IELTs or a complete lack of orgasm altogether. The current ISSM guidelines separately define primary and acquired DE. Primary DE is defined as follows: a lifelong experience of inability to ejaculate in all or almost all (75\%-100\%) occasions of coital activity, which causes distress; voluntary cessation of coital activity subsequently occurs after a variable time to avoid frustration, physical exhaustion, or genital irritation of self and/or partner; ejaculation might or might not occur by subsequent non-coital activity, including masturbation. Acquired $\mathrm{DE}$ is defined as follows: a distressing lengthening of ejaculatory latency that occurs in most $(>50 \%)$ coital experiences after a period of normal ejaculatory function and/or a clinically meaningful change that results in distress; voluntary cessation of coital activity subsequently occurs after a variable period to avoid further distress; ejaculation might or might not occur by subsequent non-coital activity, including masturbation; an ejaculation occurs independent of the sensation of an orgasm (clinical principle). ${ }^{3}$ The prevalence of DE seems to vary from study to study. A 2001 review by Simons et al. on the prevalence of sexual dysfunction found rates of DE to range anywhere from $0-8 \% .^{70}$ This discrepancy may be due to inconsistencies between how each study defines DE (primary vs. acquired vs. both). Finding DE prevalence in younger men is further complicated by the fact that most studies of DE look at older male populations or general populations. However, a 1999 study by Laumann et al. broke down the rate of DE by age and found it to affect 7\% of men aged 18-39 and 9\% of men aged 40-59. Overall, the incidence and prevalence of DE is believed to have increased over the last decade due to increased SSRI use and adverse effects of ED treatment. ${ }^{71}$ We propose the use of Internet pornography as a third cause of increased DE.

\section{Organic Etiologies}

Many of the organic components of DE can be obtained by examining the opposite of what causes PE. Recall that 5-HT1A receptors are associated with short ejaculatory times and 5-HT2C receptors are associated with longer ejaculatory times. ${ }^{56}$ It follows that individuals with $\mathrm{DE}$ may have an overexpression of 5-HT2C receptors or underexpression of 5-HT1A receptors. It also follows that variable expression of 5-HT1A and 5-HT2C receptors creates a mechanism for a genetic component of DE; however, this is not the case. A study of 1,196 Finnish male twins showed no genetic influence on DE. ${ }^{58}$ However, a moderate family effect on DE was found with shared environmental effects accounting for $24 \%$ of the variance. $^{58}$ It was previously mentioned that $\mathrm{PE}$ is associated with high levels of testosterone and low levels of prolactin and thyroid-stimulating hormone (hyperthyroidism). Because DE is the opposite of $\mathrm{PE}$, decreased levels of testosterone and elevated levels of prolactin and thyroid-stimulating hormone are expected. To prove this, Corona et al. evaluated 2,652 patients for mild to severe PE and DE. As expected, prolactin and thyroid-stimulating hormone increased from patients exhibiting severe $\mathrm{PE}$ to patients exhibiting severe DE, and the opposite was observed for testosterone. $^{72}$

\section{Psychogenic Etiologies}

The psychogenic components of DE have been compiled into four categories by Althof based on similar ideas and overlapping evidence. ${ }^{73}$ They are as follows:

Althof's Psychogenic Theories of DE

1) Insufficient mental and physical stimulation

2) Atypical masturbatory patterns

3) Disguised and subtle desire disorder masquerading as an ejaculatory disorder

4) Outgrowth of psychic conflict

Theory one is often associated with aging and diminished penile sensation. Because this is a review of sexual dysfunction in young men, it will not be covered here. Theory two revolves around disparities between fantasy during masturbation and sex in reality. Additionally, it may be caused by a masturbation technique not similar to normal oral or vaginal sex. It is best exemplified through a particular case study: Bronner et al. interviewed a 22-year-old male presenting with DE who, despite having firm erections during intravaginal sex, was unable to ejaculate unless self-stimulating. When asked about his masturbatory method, he revealed 
that he normally attaches a vacuum hose to his penis and moves it back and forth until ejaculation. This sensation is too removed from the feelings experienced during intercourse, and so the patient was not able to ejaculate with a partner. ${ }^{74}$ In the third theory of DE, men prefer masturbation over sexual intercourse. Voon et al. studied 19 young men with compulsive sexual behavior (CSB) and compared them to age-matched, healthy peers. Compared with the healthy individuals, the young men with CSB were found to have greater impairments of sexual arousal in relationships, but not with sexually explicit material. ${ }^{75}$ It is easy to imagine how extended impairment of arousal in intimate relationships combined with normal functioning arousal when masturbating to pornographic content can lead to the preferential choice of masturbation. In theory four, outgrowths of psychic conflict cause the man to experience DE. These conflicts can include loss of selfesteem, fear of ejaculation, religious guilt, fear of impregnation, unwillingness to defile a partner with semen, fear of harm from female genitals, hostility towards the partner, and performance anxiety. ${ }^{73}$

\section{Role of Pornography in DE}

Over the last decade, a large increase in the prevalence and accessibility of Internet pornography has provided increased causes of DE associated with Althof's second and third theory. Reports from 2008 found on average $14.4 \%$ of boys were exposed to pornography before the age of 13 and $5.2 \%$ of people viewed pornography at least daily. ${ }^{76}$ A 2016 study revealed that these values had both increased to $48.7 \%$ and $13.2 \%$, respectively. ${ }^{76}$ An earlier age of first pornographic exposure contributes to $\mathrm{DE}$ through its relationship with patients exhibiting CSB. Voon et al. found that young men with CSB had viewed sexually explicit material at an earlier age than their agecontrolled healthy peers. ${ }^{75}$ As previously mentioned, young men with CSB can fall victim to Althof s third theory of DE and preferentially choose masturbation over partnered sex due to a lack of arousal in relationships. An increased number of men watching pornographic material daily also contributes to $\mathrm{DE}$ through Althof's third theory. In a study of 487 male college students, Sun et al. found associations between the use of pornography and a decreased self-reported enjoyment of sexually intimate behaviors with real-life partners. ${ }^{76}$ These individuals are at an elevated risk of preferentially choosing masturbation over sexual encounters, as demonstrated in a case report by Park et al. A 20-year-old enlisted male presented with difficulty achieving orgasm with his fiancée for the previous six months. A detailed sexual history revealed that the patient relied on Internet pornography and use of a sex toy described as a "fake vagina" to masturbate while deployed. Over time, he required content of an increasingly graphic or fetish nature to orgasm. He admitted that he found his fiancée attractive but preferred the feeling of his toy because he found it more stimulating that real intercourse. ${ }^{77}$ An increase in the accessibility of Internet pornography places younger men at risk of developing $\mathrm{DE}$ through Althof s second theory, as demonstrated in the following case report: Bronner et al. interviewed a 35-year-old healthy man presenting with complaints of no desire to have sex with his girlfriend despite being mentally and sexually attracted to her. A detailed sexual history revealed that this scenario had happened with the past 20 women he tried to date. He reported extensive use of pornography since adolescence that initially consisted of zoophilia, bondage, sadism, and masochism, but eventually progressed to transgender sex, orgies, and violent sex. He would visualize the pornographic scenes in his imagination to function sexually with women, but that gradually stopped working. ${ }^{74}$ The gap between the patient's pornographic fantasies and real life became too large, causing a loss of desire. According to Althof, this will present as DE in some patients. ${ }^{73}$ This recurring theme of requiring pornographic content of an increasingly graphic or fetish nature to orgasm is defined by Park et al. as hyperactivity. As a man sensitizes his sexual arousal to pornography, sex in real life no longer activates the proper neurological pathways to ejaculate (or produce sustained erections in the case of ED). ${ }^{77}$

Medication Interactions

One of the main types of medication to treat PE is SSRIs. Unsurprisingly, SSRIs have been shown to cause DE. In a study of 2,040 men with sexual dysfunction, SSRI use was associated with a seven-fold risk for DE. ${ }^{78}$ The believed mechanism is increased activation of the 5HT2C serotonin receptor causing a lengthened ejaculatory time. ${ }^{57}$

\section{Treatment of DE}

Briefly, treatment of DE will be largely dependent on whether the root of the patient's problem is organic or psychogenic. Endocrine therapy can be used to balance out hormone levels. Cabergoline can be used to reduce prolactin levels, ${ }^{79}$ and testosterone replacement therapy with long-acting testosterone undecanoate can be used to supplement low testosterone..$^{80}$ Jenkins et al. reviewed several other medications associated with alleviating $\mathrm{DE}$, including bupropion, cyproheptadine, amantadine, yohimbine, and oxytocin. ${ }^{81}$ Althof suggests treatments for each of his four psychogenic theories: vibrator stimulation, enhancing mental arousal, and pelvic thrusting are recommended for treating insufficient mental and physical stimulation; masturbatory retraining and realignment of sexual fantasies for treating atypical masturbatory patterns; change of orientation from self to partner and less focus on pleasing partner for treating disguised and subtle desire disorder masquerading as an ejaculatory disorder; and psychotherapy targeting areas of conflict for outgrowth of psychic conflict. ${ }^{73}$ 


\section{Conclusions}

Sexual dysfunction is a debilitating condition, especially in young men who are assumed to be in their sexual prime. Over the last decade, there has been an increase in the number of young men presenting to men's health clinics with sexual dysfunction. This may be due to a lessening of social stigma associated with receiving treatment, an increase in the occurrence of these problems, or both. Regardless, clinicians must be prepared to consult appropriately with these patients and understand the specific disorders they are experiencing. Advent of new diagnostic tools and pharmacotherapy have revealed that sexual dysfunction in this young population is not as strictly psychogenic in nature as it was once believed to be. In reality, these dysfunctions often have organic components that cause concomitant psychogenic issues, which then exacerbate the original condition. Identifying young men with sexual dysfunction in early stages will allow for treatment before these psychological issues become too deeply ingrained. As more clinicians begin to understand the complex nature of these conditions, more young men will begin receiving the proper treatment they need in order to regain control of their sexual lives.

\section{Acknowledgments}

All authors are going to thank all the participants and researchers who helped us in this study.

\section{Authors' Contributions}

All authors contributed equally to this study.

\section{Conflict of Interest Disclosures}

All authors declare no conflicts of interest.

\section{Funding}

None.

\section{References}

1. Althof SE, Needle RB. Psychological factors associated with male sexual dysfunction: screening and treatment for the urologist. Urol Clin North Am. 2011;38(2):141-6. doi: 10.1016/j.ucl.2011.02.003. pmid: 21621080.

2. Reed-Maldonado $A B$, Lue TF. A syndrome of erectile dysfunction in young men? Transl Androl Urol. 2016;5(2):228-34. doi: 10.21037/tau.2016.03.02. pmid: 27141452.

3. McCabe MP, Sharlip ID, Atalla E, Balon R, Fisher AD, Laumann $E$, et al. Definitions of Sexual Dysfunctions in Women and Men: A Consensus Statement From the Fourth International Consultation on Sexual Medicine 2015. J Sex Med. 2016;13(2):135-43. doi: 10.1016/j.jsxm.2015.12.019. pmid: 26953828.

4. Feldman HA, Goldstein I, Hatzichristou DG, Krane RJ, McKinlay JB. Impotence and its medical and psychosocial correlates: results of the Massachusetts Male Aging Study. J Urol. 1994;151(1):54-61. pmid: 8254833.

5. O'Sullivan LF, Brotto LA, Byers ES, Majerovich JA, Wuest JA. Prevalence and characteristics of sexual functioning among sexually experienced middle to late adolescents. J Sex Med. 2014;11(3):630-41. doi: 10.1111/jsm.12419. pmid: 24418498.
6. Martins FG, Abdo CHN. Erectile dysfunction and correlated factors in Brazilian men aged 18-40 years. J Sex Med. 2010;7(6):2166-73. doi: 10.1111/j.1743-6109.2009.015 42.x. pmid: 19889149.

7. Wilcox SL, Redmond S, Hassan AM. Sexual functioning in military personnel: preliminary estimates and predictors. J Sex Med. 2014;11(10):2537-45. doi: 10.1111/jsm.12643. pmid: 25042933.

8. Laumann EO, Paik A, Rosen RC. Sexual dysfunction in the United States: prevalence and predictors. JAMA. 1999;281(6):537-44. doi: 10.1001/jama.281.6.537. pmid: 10022110.

9. Rastrelli G, Maggi M. Erectile dysfunction in fit and healthy young men: psychological or pathological? Translational Andrology and Urology. 2017;6(1):79-90. doi: 10.21037/tau.2016.09.06. pmid: PMC5313296.

10. Caskurlu T, Tasci Al, Resim S, Sahinkanat T, Ergenekon E. The etiology of erectile dysfunction and contributing factors in different age groups in Turkey. Int J Urol. 2004;11(7):5259. doi: 10.1111/j.1442-2042.2004.00837.x. pmid: 15242362.

11. Donatucci CF, Lue TF. Erectile dysfunction in men under 40: etiology and treatment choice. Int J Impot Res. 1993;5(2):97103. pmid: 8348217.

12. Ralph D, McNicholas T. UK management guidelines for erectile dysfunction. BMJ. 2000;321(7259):499-503. pmid: 10948037.

13. Papagiannopoulos D, Khare N, Nehra A. Evaluation of young men with organic erectile dysfunction. Asian Journal of Andrology. 2015;17(1):11-6. doi: 10.4103/1008682X.139253. pmid: PMC4291852.

14. Fedele D, Bortolotti A, Coscelli C, Santeusanio F, Chatenoud $\mathrm{L}$, Colli $\mathrm{E}$, et al. Erectile dysfunction in type 1 and type 2 diabetics in Italy. On behalf of Gruppo Italiano Studio Deficit Erettile nei Diabetici. Int J Epidemiol. 2000;29(3):524-31. pmid: 10869326.

15. Radicioni AF, Ferlin A, Balercia G, Pasquali D, Vignozzi L, Maggi $M$, et al. Consensus statement on diagnosis and clinical management of Klinefelter syndrome. J Endocrinol Invest. 2010;33(11):839-50. doi: 10.1007/BF03350351. pmid: 21293172.

16. Nguyen HMT, Gabrielson AT, Hellstrom WJG. Erectile Dysfunction in Young Men-A Review of the Prevalence and Risk Factors. Sex Med Rev. 2017;5(4):508-20. doi: 10.1016/j.sxmr.2017.05.004. pmid: 28642047.

17. Pan L, Xia X, Feng Y, Jiang C, Cui Y, Huang Y. Exposure of juvenile rats to the phytoestrogen daidzein impairs erectile function in a dose-related manner in adulthood. J Androl. 2008;29(1):55-62. doi: 10.2164/jandrol.107.003392. pmid: 17673432.

18. Siepmann T, Roofeh J, Kiefer FW, Edelson DG. Hypogonadism and erectile dysfunction associated with soy product consumption. Nutrition. 2011;27(7-8):859-62. doi: 10.1016/j.nut.2010.10.018. pmid: 21353476.

19. Sommer F, Goldstein I, Korda JB. Bicycle riding and erectile dysfunction: a review. J Sex Med. 2010;7(7):2346-58. doi: 10.1111/j.1743-6109.2009.01664.x. pmid: 20102446.

20. Andersen KV, Bovim G. Impotence and nerve entrapment in long distance amateur cyclists. Acta Neurol Scand. 1997;95(4):233-40. pmid: 9150814.

21. Michiels M, Van der Aa F. Bicycle riding and the bedroom: can riding a bicycle cause erectile dysfunction? Urology. 2015;85(4):725-30. doi: 10.1016/j.urology.2014.12.034. pmid: 25681833.

22. Yao F, Huang Y, Zhang Y, Dong Y, Ma H, Deng C, et al. Subclinical endothelial dysfunction and low-grade inflammation play roles in the development of erectile dysfunction in young men with low risk of coronary heart disease. Int J Androl. 2012;35(5):653-9. doi: 10.1111/j.1365 -2605.2012.01273.x. pmid: 22519624. 
23. Balercia G, Boscaro M, Lombardo F, Carosa E, Lenzi A, Jannini EA. Sexual symptoms in endocrine diseases: psychosomatic perspectives. Psychother Psychosom. 2007;76(3):134-40. doi: 10.1159/000099840. pmid: 17426412.

24. Ludwig W, Phillips M. Organic causes of erectile dysfunction in men under 40. Urol Int. 2014;92(1):1-6. doi: 10.1159/000354931. pmid: 24281298.

25. Krassas GE, Tziomalos K, Papadopoulou F, Pontikides N, Perros P. Erectile dysfunction in patients with hyper- and hypothyroidism: how common and should we treat? J Clin Endocrinol Metab. 2008;93(5):1815-9. doi: 10.1210/jc.2 007-2259. pmid: 18270255.

26. Keller JJ, Liang YC, Lin HC. Association between multiple sclerosis and erectile dysfunction: a nationwide case-control study. J Sex Med. 2012;9(7):1753-9. doi: 10.1111/j.17436109.2012.02746.x. pmid: 22548978.

27. Keller J, Chen YK, Lin HC. Association between epilepsy and erectile dysfunction: evidence from a population-based study. J Sex Med. 2012;9(9):2248-55. doi: 10.1111/j.17436109.2012.02670.x. pmid: 22429815.

28. Mallet R, Tricoire JL, Rischmann P, Sarramon JP, Puget J, Malavaud B. High prevalence of erectile dysfunction in young male patients after intramedullary femoral nailing. Urology. 2005;65(3):559-63. doi: 10.1016/j.urology.2004. 10.002. pmid: 15780376.

29. Siddiqui MA, Peng B, Shanmugam N, Yeo W, Fook-Chong $\mathrm{S}$, Li Tat JC, et al. Erectile dysfunction in young surgically treated patients with lumbar spine disease: a prospective follow-up study. Spine (Phila Pa 1976). 2012;37(9):797-801. doi: 10.1097/BRS.0b013e318232601c. pmid: 21912318.

30. Corona G, Ricca V, Bandini E, Mannucci E, Petrone L, Fisher $\mathrm{AD}$, et al. Association between psychiatric symptoms and erectile dysfunction. J Sex Med. 2008;5(2):458-68. doi: 10.1111/j.1743-6109.2007.00663.x. pmid: 18004996.

31. Bandini E, Fisher AD, Corona G, Ricca V, Monami M, Boddi $\checkmark$, et al. Severe depressive symptoms and cardiovascular risk in subjects with erectile dysfunction. J Sex Med. 2010;7(10):3477-86. doi: 10.1111/j.1743-6109.2010.019 36.x. pmid: 20633210

32. Smith JF, Breyer BN, Eisenberg ML, Sharlip ID, Shindel AW. Sexual function and depressive symptoms among male North American medical students. J Sex Med. 2010;7(12):3909-17. doi: 10.1111/j.1743-6109.2010.0203 3.x. pmid: 21059174.

33. Mialon A, Berchtold A, Michaud PA, Gmel G, Suris JC. Sexual dysfunctions among young men: prevalence and associated factors. J Adolesc Health. 2012;51(1):25-31. doi: 10.1016/j.jadohealth.2012.01.008. pmid: 22727073.

34. Jern P, Gunst A, Sandnabba K, Santtila P. Are early and current erectile problems associated with anxiety and depression in young men? A retrospective self-report study. J Sex Marital Ther. 2012;38(4):349-64. doi: 10.1080/0092623X.2012.665818. pmid: 22712819.

35. Yafi $F A$, Jenkins $L$, Albersen $M$, Corona $G$, Isidori $A M$, Goldfarb S, et al. Erectile dysfunction. Nat Rev Dis Primers. 2016;2:16003. doi: 10.1038/nrdp.2016.3. pmid: 27188339.

36. Bala A, Nguyen HMT, Hellstrom WJG. Post-SSRI Sexual Dysfunction: A Literature Review. Sex Med Rev. 2018;6(1):29-34. doi: 10.1016/j.sxmr.2017.07.002. pmid: 28778697.

37. Khanzada U, Khan SA, Hussain M, Adel H, Masood K, Adil $\mathrm{SO}$, et al. Evaluation of the Causes of Erectile Dysfunction in Patients Undergoing Penile Doppler Ultrasonography in Pakistan. World J Mens Health. 2017;35(1):22-7. doi: 10.5534/wjmh.2017.35.1.22. pmid: 28459144

38. Gleason JM, Slezak JM, Jung H, Reynolds K, Van den Eeden SK, Haque R, et al. Regular nonsteroidal anti-inflammatory drug use and erectile dysfunction. J Urol. 2011;185(4):138893. doi: 10.1016/j.juro.2010.11.092. pmid: 21334642.

39. Kaufman KD, Olsen EA, Whiting D, Savin R, DeVillez R,
Bergfeld W, et al. Finasteride in the treatment of men with androgenetic alopecia. Finasteride Male Pattern Hair Loss Study Group. J Am Acad Dermatol. 1998;39(4 Pt 1):578-89. doi: https://doi.org/10.1016/S0190-9622(98)70007-6. pmid: 9777765.

40. Civardi C, Collini A, Gontero P, Monaco F. Vasogenic erectile dysfunction Topiramate-induced. Clin Neurol Neurosurg. 2012;114(1):70-1. doi: 10.1016/j.clineuro.2011 .07.018. pmid: 21868149 .

41. Mykoniatis I, Grammatikopoulou MG, Bouras E, Karampasi E, Tsionga A, Kogias A, et al. Sexual Dysfunction Among Young Men: Overview of Dietary Components Associated With Erectile Dysfunction. J Sex Med. 2018;15(2):176-82. doi: 10.1016/j.jsxm.2017.12.008. pmid: 29325831.

42. Austoni $E$, Mirone $V$, Parazzini $F$, Fasolo CB, Turchi $P$, Pescatori ES, et al. Smoking as a risk factor for erectile dysfunction: data from the Andrology Prevention Weeks 2001-2002 a study of the Italian Society of Andrology (s.l.a.). Eur Urol. 2005;48(5):810-7; discussion 7-8. doi: 10.1016/j.eururo.2005.03.005. pmid: 16202509.

43. He J, Reynolds K, Chen J, Chen CS, Wu X, Duan X, et al. Cigarette smoking and erectile dysfunction among Chinese men without clinical vascular disease. Am J Epidemiol. 2007;166(7):803-9. doi: 10.1093/aje/kwm154. pmid: 17623 743.

44. Mirone V, Imbimbo C, Bortolotti A, Di Cintio E, Colli E, Landoni $\mathrm{M}$, et al. Cigarette smoking as risk factor for erectile dysfunction: results from an Italian epidemiological study. Eur Urol. 2002;41(3):294-7. pmid: 12180231.

45. Millett C, Wen LM, Rissel C, Smith A, Richters J, Grulich A, et al. Smoking and erectile dysfunction: findings from a representative sample of Australian men. Tob Control. 2006;15(2):136-9. doi: 10.1136/tc.2005.015545. pmid: 16565463.

46. Gades NM, Nehra A, Jacobson DJ, McGree ME, Girman CJ, Rhodes $\mathrm{T}$, et al. Association between smoking and erectile dysfunction: a population-based study. Am J Epidemiol. 2005;161(4):346-51. doi: 10.1093/aje/kwi052. pmid: 15692 078.

47. Yang $\mathrm{Y}$, Liu R, Jiang $\mathrm{H}$, Hong $\mathrm{K}$, Zhao L, Tang $\mathrm{W}$, et al. Association Between Dosage Frequency and the Treatment Outcomes of Sildenafil in Young and Middle-aged Men With Erectile Dysfunction: A Chinese, Multicenter, Observational Study. Urology. 2015;86(1):62-7. doi: 10.1016/j.urology .2015.03.011. pmid: 26142584.

48. Kennedy SH, Dugre H, Defoy I. A multicenter, double-blind, placebo-controlled study of sildenafil citrate in Canadian men with erectile dysfunction and untreated symptoms of depression, in the absence of major depressive disorder. Int Clin Psychopharmacol. 2011;26(3):151-8. doi: 10.1097/YIC.0b013e32834309fc. pmid: 21471773.

49. Simonelli C, Tripodi F, Cosmi V, Rossi R, Fabrizi A, Silvaggi $\mathrm{C}$, et al. What do men and women ask a helpline on sexual concerns? Results of an Italian telephone counselling service. Int J Clin Pract. 2010;64(3):360-70. doi: 10.1111/j.1742-1241.2009.02269.x. pmid: 20456175.

50. Lee SW, Lee JH, Sung HH, Park HJ, Park JK, Choi SK, et al. The prevalence of premature ejaculation and its clinical characteristics in Korean men according to different definitions. Int J Impot Res. 2013;25(1):12-7. doi: 10.1038/ijir.2012.27. pmid: 22931761.

51. Hwang I, Yang DO, Park K. Self-Reported Prevalence of and Attitudes toward Premature Ejaculation in a CommunityBased Study of Married Couples. World J Mens Health. 2013;31(1):70-5. doi: 10.5534/wjmh.2013.31.1.70. pmid: 23658869.

52. Shaeer O. The global online sexuality survey (GOSS): The United States of America in 2011 Chapter III--Premature ejaculation among English-speaking male Internet users. J Sex Med. 2013;10(7):1882-8. doi: 10.1111/jsm.12187. pmid: 23668379. 
53. Waldinger MD. Premature ejaculation: state of the art. Urol Clin North Am. 2007;34(4):591-9, vii-viii. doi: 10.1016/j.ucl.2007.08.011. pmid: 17983899.

54. Bartoletti R, Cai T, Mondaini N, Dinelli N, Pinzi N, Pavone $\mathrm{C}$, et al. Prevalence, incidence estimation, risk factors and characterization of chronic prostatitis/chronic pelvic pain syndrome in urological hospital outpatients in Italy: results of a multicenter case-control observational study. J Urol. 2007;178(6):2411-5; discussion 5. doi: 10.1016/j.juro.2007. 08.046. pmid: 17937946.

55. Screponi E, Carosa E, Di Stasi SM, Pepe M, Carruba G, Jannini EA. Prevalence of chronic prostatitis in men with premature ejaculation. Urology. 2001;58(2):198-202. doi: https://doi.org/10.1016/S0090-4295(01)01151-7. pmid: 11489699.

56. Ahlenius S, Larsson K, Svensson L, Hjorth S, Carlsson A, Lindberg $\mathrm{P}$, et al. Effects of a new type of $5-\mathrm{HT}$ receptor agonist on male rat sexual behavior. Pharmacol Biochem Behav. 1981;15(5):785-92. doi: https://doi.org/10.1016/009 1-3057(81)90023-X. pmid: 6458826.

57. Waldinger MD. The neurobiological approach to premature ejaculation. J Urol. 2002;168(6):2359-67. doi: 10.1097/01.ju.0000035599.35887.8f. pmid: 12441918.

58. Jern P, Santtila P, Witting K, Alanko K, Harlaar N, Johansson $A$, et al. Premature and delayed ejaculation: genetic and environmental effects in a population-based sample of Finnish twins. J Sex Med. 2007;4(6):1739-49. doi: 10.1111/j.1743-6109.2007.00599.x. pmid: 17888070.

59. Corona G, Jannini EA, Mannucci E, Fisher AD, Lotti F, Petrone L, et al. Different testosterone levels are associated with ejaculatory dysfunction. J Sex Med. 2008;5(8):1991-8. doi: 10.1111/j.1743-6109.2008.00803.x. pmid: 18399946.

60. Podlasek CA, Mulhall J, Davies K, Wingard CJ, Hannan JL, Bivalacqua TJ, et al. Translational Perspective on the Role of Testosterone in Sexual Function and Dysfunction. The journal of sexual medicine. 2016;13(8):1183-98. doi: 10.1016/j.jsxm.2016.06.004. pmid: PMC5333763.

61. Sansone A, Romanelli F, Jannini EA, Lenzi A. Hormonal correlations of premature ejaculation. Endocrine. 2015;49(2):333-8. doi: 10.1007/s12020-014-0520-7. pmid: 25552341.

62. Corona G, Mannucci E, Jannini EA, Lotti F, Ricca V, Monami $M$, et al. Hypoprolactinemia: a new clinical syndrome in patients with sexual dysfunction. J Sex Med. 2009;6(5):145766. doi: 10.1111/j.1743-6109.2008.01206.x. pmid: 192107 05.

63. Carani C, Isidori AM, Granata A, Carosa E, Maggi M, Lenzi A, et al. Multicenter study on the prevalence of sexual symptoms in male hypo- and hyperthyroid patients. J Clin Endocrinol Metab. 2005;90(12):6472-9. doi: 10.1210/jc.2005-1135. pmid: 16204360.

64. McMahon CG, Jannini EA, Serefoglu EC, Hellstrom WJG. The pathophysiology of acquired premature ejaculation. Translational Andrology and Urology. 2016;5(4):434-49. doi: 10.21037/tau.2016.07.06. pmid: PMC5001985.

65. Dunn KM, Croft PR, Hackett Gl. Association of sexual problems with social, psychological, and physical problems in men and women: a cross sectional population survey. Journal of Epidemiology and Community Health. 1999;53(3):144-8. pmid: PMC1756846.

66. Hartmann U, Schedlowski M, Kruger TH. Cognitive and partner-related factors in rapid ejaculation: differences between dysfunctional and functional men. World J Urol.
2005;23(2):93-101. doi: 10.1007/s00345-004-0490-0. pmid: 15947962.

67. el-Sakka AI. Severity of erectile dysfunction at presentation: effect of premature ejaculation and low desire. Urology. 2008;71(1):94-8. doi: 10.1016/j.urology.2007.09.006. pmid: 18242373.

68. Ciocca G, Limoncin E, Mollaioli D, Gravina GL, Di Sante S, Carosa $E$, et al. Integrating psychotherapy and pharmacotherapy in the treatment of premature ejaculation. Arab Journal of Urology. 2013;11(3):305-12. doi: 10.1016/j.aju.2013.04.011. pmid: PMC4443008.

69. Kalejaiye O, Almekaty K, Blecher G, Minhas S. Premature ejaculation: challenging new and the old concepts. F1000Research. 2017;6:2084. doi: 10.12688/f1000researc h.12150.1. pmid: PMC5717471.

70. Simons J, Carey MP. Prevalence of Sexual Dysfunctions: Results from a Decade of Research. Archives of sexual behavior. 2001;30(2):177-219. pmid: PMC2426773.

71. Parelman MA. Regarding ejaculation, delayed and otherwise. J Androl. 2003;24(4):496. pmid: 12826687.

72. Corona G, Jannini EA, Lotti F, Boddi V, De Vita G, Forti G, et al. Premature and delayed ejaculation: two ends of a single continuum influenced by hormonal milieu. Int J Androl. 2011;34(1):41-8. doi: 10.1111/j.13652605.2010.01059.x. pmid: 20345874.

73. Althof SE. Psychological interventions for delayed ejaculation/orgasm. Int J Impot Res. 2012;24(4):131-6. doi: 10.1038/ijir.2012.2. pmid: 22378496.

74. Bronner G, Ben-Zion IZ. Unusual masturbatory practice as an etiological factor in the diagnosis and treatment of sexual dysfunction in young men. J Sex Med. 2014;11(7):1798-806. doi: 10.1111/jsm.12501. pmid: 24674621

75. Voon V, Mole TB, Banca P, Porter L, Morris L, Mitchell S, et al. Neural Correlates of Sexual Cue Reactivity in Individuals with and without Compulsive Sexual Behaviours. PLoS ONE. 2014;9(7):e102419. doi: 10.1371/journal.pone.0102 419. pmid: PMC4094516.

76. Sun C, Bridges A, Johnson JA, Ezzell MB. Pornography and the Male Sexual Script: An Analysis of Consumption and Sexual Relations. Arch Sex Behav. 2016;45(4):983-94. doi: 10.1007/s10508-014-0391-2. pmid: 25466233.

77. Park BY, Wilson G, Berger J, Christman M, Reina B, Bishop $F$, et al. Is Internet Pornography Causing Sexual Dysfunctions? A Review with Clinical Reports. Behavioral Sciences. 2016;6(3):17. doi: 10.3390/bs6030017. pmid: PMC5039517.

78. Corona G, Ricca V, Bandini E, Mannucci E, Lotti F, Boddi V, et al. Selective serotonin reuptake inhibitor-induced sexual dysfunction. J Sex Med. 2009;6(5):1259-69. doi: 10.1111/j.1743-6109.2009.01248.x. pmid: 19473282.

79. Nickel M, Moleda D, Loew T, Rother W, Pedrosa Gil F. Cabergoline treatment in men with psychogenic erectile dysfunction: a randomized, double-blind, placebocontrolled study. Int J Impot Res. 2007;19(1):104-7. doi: 10.1038/sj.ijir.3901483. pmid: 16728967.

80. Hackett G, Cole N, Bhartia M, Kennedy D, Raju J, Wilkinson P. Testosterone replacement therapy with long-acting testosterone undecanoate improves sexual function and quality-of-life parameters vs. placebo in a population of men with type 2 diabetes. J Sex Med. 2013;10(6):1612-27. doi: 10.1111/jsm.12146. pmid: 23551886.

81. Jenkins LC, Mulhall JP. Delayed Orgasm and Anorgasmia. Fertility and sterility. 2015;104(5):1082-8. doi: 10.1016/j.fertnstert.2015.09.029. pmid: PMC4816679. 